\title{
Research Paper: Hypoglycemia in Patients With Pure Benzodiazepine Poisoning
}

\author{
Fazel Goudarzi $^{1}$ (D), Razieh Sadat Mousavi-Roknabadi' ${ }^{1,}$ (D), Maryam Abdollahpour ${ }^{3}$, Robab Sadegh $^{1}$ \\ 1. Department of Emergency Medicine, School of Medicine, Shiraz University of Medical Sciences, Shiraz, Iran. \\ 2. Emergency Medicine Research Center, Shiraz University of Medical Sciences, Shiraz, Iran. \\ 3. Student Research Committee, Department Emergency Medicine, School of Medicine, Shiraz University of Medical Sciences, Shiraz, Iran
}

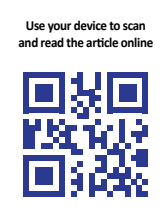

Citation: Goudarzi F, Mousavi-Roknabadi RS, Abdollahpour M, Sadegh R. Hypoglycemia in Patients With Pure Benzodiazepine Poisoning. International Journal of Medical Toxicology and Forensic Medicine. 2021; 11(2):32702. https://doi. org/10.32598/ijmtfm.v11i2.32702

doijhttps://doi.org/10.32598/ijmtfm.v11i2.32702

\section{(i) (3)}

Article info:

Received: 28 Oct 2020

First Revision: 21 Nov 2020

Accepted: 01 May 2021

Published: 15 Jun 2021

\section{ABSTRACT}

Background: Various studies investigated the effects of benzodiazepines on insulin and blood glucose levels and provided contradictory results. The present study aimed to evaluate the clinical effects of benzodiazepine poisoning on hypoglycemia.

Methods: This retrospective cross-sectional study (from 22/June/2018 to 22/December/2018) was conducted on all medical records of adult patients with benzodiazepine poisoning who were referred to Ali-Asghar Hospital. The required data were collected using a data-gathering form and then analyzed.

Results: In total, 61 patients were enrolled in this study. Furthermore, 19 (31.2\%) patients developed hypoglycemia. Besides, $50(82 \%)$ patients used benzodiazepine for a suicide attempt, i.e. higher in patients with hypoglycemia $(\mathrm{P}<0.0001)$. Multivariate logistic regression test data indicated that benzodiazepine consumption for suicide attempt $(\mathrm{OR}=47.978, \mathrm{P}=0.001,95 \% \mathrm{CI}$, $5.313-433.277)$, and the respiratory rate at the time of suicide $(\mathrm{OR}=0.549, \mathrm{P}=0.023,95 \% \mathrm{CI}$, 0.328-0.920) were predictive factors for hypoglycemia in patients with benzodiazepine poisoning.

Conclusion: Our study data suggested that $31 \%$ of patients who were poisoned with benzodiazepines developed hypoglycemia. The suicidal use of drugs and respiratory rates were predictive factors for hypoglycemia in these patients.
Benzodiazepines,

Hypoglycemia, Toxicity

\section{Introduction}

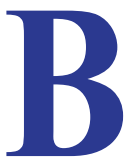

enzodiazepine is a class of drugs widely used for sedative and anti-anxiety effects [1]. Since the emergence of chlordiazepoxide, followed by diazepam in the 1960s, benzodiazepines have been used

as the main sedative and anti-anxiety drugs. This is due to their high safety profile, compared to other sedativehypnotic medications. Since then, various drugs of this class have been used for treating anxiety, seizures, insomnia, and restlessness, as well as in performing various procedures to induce sedation. Drugs of this family

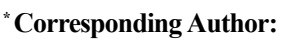

Razieh Sadat Mousavi-Roknabadi, MD.

Address: Department of Emergency Medicine, Emergency Medicine Research Center, School of Medicine, Shiraz University of Medical Sciences, Shiraz, Iran.

Tel: +98 (913) 1563018

E-mail:mousavi_razieh@sums.ac.ir
} 
induce their effects by acting on gamma-aminobutyric acid receptors [2].

Benzodiazepines can affect insulin secretion in various ways and cause glycemic dysregulation in the long run [1]. For example, the inhibitory and stimulatory effect of Gamma-Aminobutyric Acid (GABA) on insulin secretion has been extensively studied [3]. More than 50 types of drugs are produced from the benzodiazepine family [2]. Even poisoning with this drug is quite prevalent, i.e. due to their widespread use. In numerous cases, these drugs are used to commit suicide [4]. The symptoms of poisoning usually manifest as the central nervous system depression with normal or near-normal vital signs. An essential differential diagnosis of this poisoning induced by decreased level of consciousness is hypoglycemia. Therefore, after the stability of the patient's airway and the initial measures, the patients' blood glucose level should be immediately checked using a glucometer [2].

The effect of benzodiazepines on insulin and blood glucose levels has been extensively studied and provided contradictory results [5-8]. To the best of our knowledge, no studies have investigated the effect of high-dose benzodiazepines or poisoning. The present study aimed to evaluate the clinical effects of benzodiazepine poisoning on the blood glucose level.

\section{Materials and Methods}

This retrospective cross-sectional study (from 22/ June/2018 to 22/December/2018) was conducted on the medical files of all patients who were referred to AliAsghar Hospital; it is a referral hospital for poisoning in Shiraz City, Iran.

The inclusion criteria of the study were patients aged $>15$ years, with benzodiazepines poisoning (including diazepam, alprazolam, clonazepam, lorazepam, flurazepam), who were referred to our hospital during the study period. The patients with uncompleted medical files, trauma, diabetes mellitus, and insulin consumption. Besides, patients with concomitant poisoning with another drug were excluded from the study. Benzodiazepine poisoning was diagnosed by a clinical toxicologist according to the patients' medical history, decreased level of consciousness and drowsiness, physical examination, and benzodiazepine urine test. Using MedCalc and considering $\alpha=0.05, \beta=0.2$, and $P=1.16$ [9], the sample size was calculated as 59 patients.

The required data were collected in a data-gathering form, including age, gender, vital signs, the duration of hospitalization, the type and dose of the drug, the interval from poisoning to hospital arrival, the duration of the first episode of hypoglycemia, and the number of such experiences, a history of benzodiazepine consumption and the relevant reason, a history of seizures, sleep disorders, anxiety, and confusion, as well as the related outcomes. Hypoglycemia was defined as a blood glucose level of $<60 \mathrm{mg} / \mathrm{dL}$ [10].

All analyses were performed by SPSS using Chisquared and Fisher's exact tests for proportions, as well as Independent Samples t-test and Mann-Whitney U test for the mean scores. The collected results were presented as Mean \pm SD for continuous variables and were summarized in frequency (percentage) for categorical ones. Univariate and multivariate logistic regression tests (Enter) were used for calculating Odds Ratio (OR) and determining the relevant predictive factors. Two-Sided $\mathrm{P}<0.05$ and Confidence Interval (CI) of $95 \%$ were considered to be statistically significant.

The current study was approved by the local Ethics Committee (Code: IR.SUMS.MED.REC.1398.102) of Shiraz University of Medical Sciences. To consider ethical issues, the collected data were not revealed to anyone, except for the researchers.

\section{Results}

Sixty-One patients were enrolled in this study; of them. $33(65.6 \%)$ were women and their Mean \pm SD age was $31.10 \pm 1.64$ years (age range: $16-70 \mathrm{y}$ ). Totally, 19 (31.2\%) patients developed hypoglycemia; 8 (13.1\%) patients suffered for 1 time, 8 (13.1\%) for 2 times, and $3(4.9 \%)$ individuals for 3 times. The Mean \pm SD number of times for hypoglycemia experience was measured as $1.74 \pm 0.73$. Moreover, 50 (82\%) patients used benzodiazepine for a suicide attempt, i.e. higher in patients with hypoglycemia $(\mathrm{P}<0.0001)$. Additionally, sleep disorder was higher in the patients with hypoglycemia $(\mathrm{P}<0.001)$. Our results suggested that the mean respiratory rate $(\mathrm{P}=0.009)$ and $\mathrm{O}_{2}$ saturation $(\mathrm{P}=0.034)$ were significantly lower in patients with hypoglycemia. Other variables were not different between the study groups (Table 1). Alprazolam (32.8\%) and diazepam (21.3\%) were the most prevalent benzodiazepine used by the research patients. Table 2 presents the consumption dose in detail.

Multivariate logistic regression test data indicated that benzodiazepine consumption for suicide attempt $(\mathrm{OR}=47.978, \mathrm{P}=0.001,95 \% \mathrm{CI}, 5.313-433.277)$, and the respiratory rate at the time of admission $(\mathrm{OR}=0.549$, $\mathrm{P}=0.023,95 \% \mathrm{CI}, 0.328-0.920)$ were predictive factors for 
Table 1. The study patients' characteristics and the association between studied variables

\begin{tabular}{|c|c|c|c|c|c|}
\hline \multirow[b]{2}{*}{ Variable } & \multicolumn{5}{|c|}{ Mean士SD/ No. (\%) } \\
\hline & $\begin{array}{c}\text { Total } \\
(\mathrm{N}=61)\end{array}$ & $\begin{array}{l}\text { With Hypogly- } \\
\text { cemia } \\
(n=19)\end{array}$ & $\begin{array}{l}\text { Without Hypo- } \\
\text { glycemia } \\
(n=42)\end{array}$ & OR & $\mathbf{P}$ \\
\hline Age, y & $31.10 \pm 1.64$ & $29.74 \pm 11.37$ & $31.61 \pm 11.77$ & \multirow{4}{*}{0.084} & \multirow{4}{*}{0.531} \\
\hline Men & $34.24 \pm 14.52$ & $33.57 \pm 15.20$ & $34.57 \pm 14.75$ & & \\
\hline Women & $29.38 \pm 9.60$ & $26.60 \pm 8.28$ & $30.41 \pm 9.99$ & & \\
\hline $\mathrm{P}$ & 0.13 & 0.24 & 0.29 & & \\
\hline Men & $21(34.4)$ & $7(36.8)$ & $14(33.3)$ & \multirow{2}{*}{0.018} & \multirow{2}{*}{0.893} \\
\hline Women & 38 (65.6) & $12(63.2)$ & $26(66.7)$ & & \\
\hline Seizure & 0 & 0 & 0 & \multirow{4}{*}{$\begin{array}{l}-0.080 \\
0.115 \\
0.249\end{array}$} & \multirow{4}{*}{$\begin{array}{c}<0.001^{*} \\
0.38 \\
0.055\end{array}$} \\
\hline Sleep disorder & $10(16.4)$ & $4(21.1)$ & $6(14.3)$ & & \\
\hline cal history & 9 (14.8) & $4(21.1)$ & 5 (11.9) & & \\
\hline Agitation & $4(6.6)$ & $3(15.8)$ & $1(2.4)$ & & \\
\hline Alprazolam & $20(32.8)$ & $8(13.1)$ & $12(19.7)$ & \multirow{5}{*}{0.120} & \multirow{5}{*}{0.361} \\
\hline Clonazepam & $10(16.4)$ & $5(8.2)$ & $5(8.2)$ & & \\
\hline azepine & $13(21.3)$ & $3(4.9)$ & $10(16.6)$ & & \\
\hline Flurazepam & $10(16.4)$ & $1(1.6)$ & $9(14.8)$ & & \\
\hline Lorazepam & $8(13.1)$ & $2(3.3)$ & $6(9.8)$ & & \\
\hline Benzodiazepine dose & $75.16 \pm 66.11$ & $63.58 \pm 66.11$ & $80.4 \pm 66.23$ & 0.126 & 0.339 \\
\hline $\begin{array}{l}\text { Benzodiazepine consumption for suicide } \\
\text { attempt }\end{array}$ & $50(82.0)$ & $10(52.6)$ & $40(95.2)$ & -0.511 & $0<0.001^{*}$ \\
\hline Interval from poisoning to hospital arrival (h) & $2.31 \pm 1.14$ & $2.23 \pm 1.4$ & $2.34 \pm 1.03$ & 0.47 & 0.719 \\
\hline \multirow{5}{*}{$\begin{array}{l}\text { Systolic blood pressure (mmHg) } \\
\text { Diastolic blood pressure (mmHg) } \\
\text { Heart rate (per minutes) } \\
\text { Respiratory rate (per minutes) } \\
\qquad \mathrm{O}_{2} \text { saturation (\%) }\end{array}$} & $99.13 \pm 11.97$ & $96.0 \pm 11.85$ & $100.85 \pm 11.89$ & 0.177 & 0.175 \\
\hline & $59.67 \pm 5.98$ & $60.4 \pm 5.3$ & $57.8 \pm 9.6$ & 0.226 & 0.083 \\
\hline & $73.48 \pm 11.96$ & $74.11 \pm 5.1$ & $71.13 \pm 3.8$ & 0.114 & 0.388 \\
\hline & $13.2 \pm 2.43$ & $13.13 \pm 7.9$ & $11.3 \pm 9.1$ & 0.337 & $0.009^{*}$ \\
\hline & $93.10 \pm 2.51$ & $93.2 \pm 6.5$ & $92.12 \pm 3.0$ & 0.274 & $0.034^{*}$ \\
\hline $\begin{array}{l}\text { Blood glucose }(\mathrm{mg} / \mathrm{dL}) \text { at the time of admis- } \\
\text { sion }\end{array}$ & $85.86 \pm 13.64$ & $83.16 \pm 16.91$ & $87.10 \pm 11.91$ & 0.140 & 0.285 \\
\hline $\begin{array}{l}\text { The interval from poisoning to the first } \\
\text { episode of hypoglycemia (h) }\end{array}$ & $3.94 \pm 1.42$ & $3.94 \pm 1.42$ & - & - & - \\
\hline \multirow{2}{*}{$\begin{array}{c}\text { Discharge } \\
\text { Death }\end{array}$} & $61(100)$ & $19(100)$ & $42(100)$ & \multirow[b]{2}{*}{ - } & \multirow[b]{2}{*}{ - } \\
\hline & 0 & 0 & 0 & & \\
\hline
\end{tabular}


Table 2. Benzodiazepine consumption in details

\begin{tabular}{ccccc}
\hline Benzodiazepine Consumption & No. (\%) & $\begin{array}{c}\text { Mean } \pm \text { SD } \\
\text { Consumption Dose (mg) }\end{array}$ & Min Dosage (mg) & Max Dosage (mg) \\
\hline Alprazolam & $20(32.8)$ & $42.39 \pm 1.5$ & 18 & 207 \\
\hline Clonazepam & $10(16.4)$ & $35.11 \pm 9.9$ & 22 & 60 \\
\hline Diazepam & $13(21.3)$ & $61 \pm 13.06$ & 40 & 250 \\
Flurazepam & $10(16.4)$ & $52 \pm 15.33$ & 30 & 225 \\
Lorazepam & $8(13.1)$ & $20.5 \pm 6.1$ & 15 & 30 \\
Total & 100 & $75.8 \pm 2.5$ & 15 & 250 \\
\hline SD: Standard Deviation. & & & International Journal of Eorensic Medicin \\
\hline
\end{tabular}

Table 3. The results of multivariate logistic regression

\begin{tabular}{|c|c|c|c|c|c|}
\hline \multirow{2}{*}{ Variable } & \multirow{2}{*}{ OR } & \multirow{2}{*}{ SE } & \multirow{2}{*}{$\mathbf{P}$} & \multicolumn{2}{|c|}{$95 \% \mathrm{Cl}$} \\
\hline & & & & Lower & Upper \\
\hline A history of sleep disorders & 0.801 & 1.054 & 0.833 & 0.102 & 6.317 \\
\hline $\begin{array}{l}\text { Benzodiazepine consumption for suicide } \\
\text { attempt }\end{array}$ & 47.978 & 0.263 & 0.001 & 5.313 & 433.277 \\
\hline Respiratory rate (per min) & 0.549 & 0.263 & 0.023 & 0.328 & 0.920 \\
\hline $\mathrm{O}_{2}$ Saturation & 0.916 & 0.186 & 0.637 & 0.637 & 1.318 \\
\hline
\end{tabular}

hypoglycemia in patients with benzodiazepine poisoning (Table 3).

\section{Discussion}

Our study revealed that approximately $31 \%$ of patients with pure benzodiazepine poisoning developed hypoglycemia. Suicide was also the cause of $82 \%$ of benzodiazepine poisoning. Mean RR and blood oxygen saturation levels in patients with hypoglycemia were significantly lower, compared to the other patients. The results of the multivariate analysis suggested that the suicidal use of this drug and the respiratory rate were the predictors of hypoglycemia in these patients. However, characteristics, such as age, gender, type of benzodiazepine and its dosage, blood pressure, heart rate, the interval from poisoning to hospitalization, as well as the first episode of hypoglycemia provided no significant effect on the development of hypoglycemia.

Previous studies that examined the effect of benzodiazepines on blood glucose have all used low doses of these drugs and often single doses. To the best of our knowledge, studies on the effects of benzodiazepine poisoning on blood glucose level- especially in the pure form and without other drugs are scarce. Nzor et al. explored Wistar rats and observed no significant decrease in serum glucose concentration at different concentrations of di- azepam and bromazepam [7], which contradicts the findings of the present study.

Chia-Ling Lin et al. reported that the risk of diabetes mellitus is higher in patients using zolpidem and benzodiazepines [11]. Afkhami Ardekani et al., in a parallel clinical trial on 66 patients with type 2 diabetes found that alprazolam was effective in regulating fasting, postprandial, and HbA1c hyperglycemia [8]. The difference between these studies and the present study is that all the in vivo or in vitro investigations were in the target group with diabetes; however, patients with diabetes were excluded from our study either by taking insulin or antidiabetic drugs.

Chevassus et al. found that single-dose benzodiazepines, especially clonazepam, could alter insulin secretion and insulin sensitivity in healthy patients [1]. Mohseni et al. reported that administrating $5 \mathrm{mg}$ oral diazepam the night before surgery could significantly reduce patients' blood glucose levels during and after surgery [5]. In a Randomized Clinical Trial (RCT) on 45 non-diabetic patients with panic disorder, Moghadamnia et al. found that the treatment with alprazolam could increase fasting and 2-hour postprandial glucose levels [12].

Nevertheless, Giordano et al. studied 8 healthy individuals and found that alprazolam presented no effect on 
hypoglycemia-induced glucose changes [13]. Shcaira et al. explored individuals with non-insulin-dependent diabetes and a healthy group who underwent dental procedures. Accordingly, they argued that a single dose of 5 $\mathrm{mg}$ of diazepam before dental procedures significantly altered their blood glucose levels [6].

One limitation of this retrospective study was that some information was not accurately recorded in the patients' medical files. Other limitations were the insufficient number of patients with pure benzodiazepine poisoning; the inability of patients and their relatives to provide a correct medical history of the patient, the type of drug, and the time of taking medicine. It is recommended that studies be conducted on larger sample size and multicenter concerning the effect of benzodiazepine poisoning on blood glucose levels.

\section{Conclusion}

Our study data indicated that $31 \%$ of patients who were poisoned with benzodiazepines developed hypoglycemia. Suicide attempt was the cause of $82 \%$ of benzodiazepine poisoning. The suicidal use of drugs and respiratory rates were higher in patients with hypoglycemia. It is suggested that hypoglycemia be considered in treating patients with benzodiazepine poisoning, and blood glucose levels be measured several times and at regular intervals in this population.

\section{Ethical Considerations}

\section{Compliance with ethical guidelines}

The current study was approved by the Ethics Committee of Shiraz University of Medical Sciences (Code: IR.SUMS. MED.REC.1398.102). To consider ethical issues, the collected data were not revealed to anyone, except for the researchers.

\section{Funding}

The present article was extracted from the MD. dissertation of third author at Student Research Committee, Department Emergency Medicine, School of Medicine, Shiraz University of Medical Sciences, Shiraz (Grant No. 18251).

\section{Author's contributions}

Conceptualization: Fazel Goudarzi; Methodology: Fazel Goudarzi, Razieh Sadat Mousavi-Roknabadi; Data collection: Fazel Goudarzi, Maryam Abdollahpour; Writing - origi- nal draft: Fazel Goudarzi, Razieh Sadat Mousavi-Roknabadi, Maryam Abdollahpour, Robab Sadegh; Writing - review \& editing: Fazel Goudarzi, Razieh Sadat Mousavi-Roknabadi, Maryam Abdollahpour, Robab Sadegh.

\section{Conflict of interest}

The authors declared no conflict of interest.

\section{References}

[1] Chevassus H, Mourand I, Molinier N, Lacarelle B, Brun JF Petit P. Assessment of single-dose benzodiazepines on insulin secretion, insulin sensitivity and glucose effectiveness in healthy volunteers: A double-blind, placebo-controlled, randomized cross-over trial [ISRCTN08745124]. BMC Clin Pharmacol. 2004; 4:3. [DOI:10.1186/1471-2210-4-3] [PMID]

[2] Kang M, Galuska MA, Ghassemzadeh S. Benzodiazepine toxicity [monograph online]. Treasure Island (FL): StatPearls Publishing; 2021. https://pubmed.ncbi.nlm.nih. gov/29489152/

[3] Gramaglia E, Ramella Gigliardi V, Olivetti I, Tomelini M, Belcastro S, Calvi E, et al. Impact of short-term treatment with benzodiazepines and imidazopyridines on glucose metabolism in healthy subjects. J Endocrinol Invest. 2014; 37(2):203-6. [DOI:10.1007/s40618-013-0016-y] [PMID]

[4] Geulayov G, Ferrey A, Casey D, Wells C, Fuller A, Bankhead $\mathrm{C}$, et al. Relative toxicity of benzodiazepines and hypnotics commonly used for self-poisoning: An epidemiological study of fatal toxicity and case fatality. J Psychopharmacol. 2018; 32(6):654-62. [DOI:10.1177/0269881118754734] [PMID]

[5] Mohseni G, Ranjbar A, Rezaei M. Oral diazepam effect on surgical patient's postoperative blood sugar. Ann Biol Res. 2012; 3(9):4382-5. https:/ / www.scholarsresearchlibrary. com/articles/oral-diazepam-effect-on-surgical-patientspostoperative-blood-sugar.pdf

[6] Schaira VR, Ranali J, Saad MJ, de Oliveira PC, Ambrosano GM, Volpato MC. Influence of diazepam on blood glucose levels in nondiabetic and non-insulin-dependent diabetic subjects under dental treatment with local anesthesia. Anesth Prog. 2004; 51(1):14-8. [PMID] [PMCID]

[7] Nzor JN, Uwakwe AA, Onuoha SC. Impact of benzodiazepines administration on selected biochemical parameters of albino Wistar rats (Rattus rattus). Egyp Pharm J. 2018; 17(1):40-7. [DOI:10.4103/epj.epj_26_17]

[8] Afkhami Ardekani M, Shojaoddini Ardekani A, Soltani V, Molanoori E. Comparing the effects of Fluoxetine and $\mathrm{Al}$ prazolam on blood glucose in patients with type 2 diabetes. J Inflamm Dis. 2008; 12(1):21-9. http://journal.qums.ac.ir/ article-1-15-fa.html

[9] Allabi AC, Klikpo E, Lonmandon SC, Tognide CM. Pharmacovigilance of neuroleptics and benzodiazepines in the psychiatric teaching hospital of Benin republic. J Pharmacovigil. 2017; 5(6). [DOI:10.4172/2329-6887.1000249] 
[10] Perlmuter LC, Flanagan BP, Shah PH, Singh SP. Glycemic control and hypoglycemia: Is the loser the winner? Diabetes Care. 2008; 31(10):2072-6. [DOI:10.2337/dc08-1441] [PMID] [PMCID]

[11] Lin CL, Yeh MC, Harnod T, Lin CL, Kao CH. Risk of type 2 diabetes in patients with nonapnea sleep disorders in using different types of hypnotics: A Population-Based Retrospective Cohort Study. Medicine (Baltimore). 2015; 94(38):e1621. [DOI:10.1097/MD.0000000000001621] [PMID] [PMCID]

[12] Moghadamnia AA, Moudi S, Tamaskani N, Saleki M, Hamidia A, Mouodi M, et al. Effects of Alprazolam and Clonazepam on blood sugar in patients with panic disorder. Cyprus J of Med Sci. 2019; 4 (3):195-200. [DOI:10.5152/cjms.2019.716]

[13] Giordano R, Grottoli S, Brossa P, Pellegrino M, Destefanis $S$, Lanfranco $F$, et al. Alprazolam (a benzodiazepine activating GABA receptor) reduces the neuroendocrine responses to insulin-induced hypoglycaemia in humans. Clin Endocrinol (Oxf). 2003; 59(3):314-20. [DOI:10.1046/j.13652265.2003.01847.x] [PMID] 